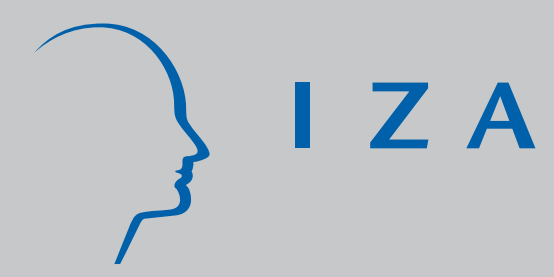

IZA DP No. 3623

Preparing for Policy Changes: Social Security Expectations and Pension Scheme Participation

Karen van der Wiel

J uly 2008 


\title{
Preparing for Policy Changes: Social Security Expectations and Pension Scheme Participation
}

\author{
Karen van der Wiel \\ Tilburg University and IZA
}

\author{
Discussion Paper No. 3623 \\ July 2008
}

IZA

P.O. Box 7240

53072 Bonn

Germany

Phone: +49-228-3894-0

Fax: +49-228-3894-180

E-mail: iza@iza.org

Any opinions expressed here are those of the author(s) and not those of IZA. Research published in this series may include views on policy, but the institute itself takes no institutional policy positions.

The Institute for the Study of Labor (IZA) in Bonn is a local and virtual international research center and a place of communication between science, politics and business. IZA is an independent nonprofit organization supported by Deutsche Post World Net. The center is associated with the University of Bonn and offers a stimulating research environment through its international network, workshops and conferences, data service, project support, research visits and doctoral program. IZA engages in (i) original and internationally competitive research in all fields of labor economics, (ii) development of policy concepts, and (iii) dissemination of research results and concepts to the interested public.

IZA Discussion Papers often represent preliminary work and are circulated to encourage discussion. Citation of such a paper should account for its provisional character. A revised version may be available directly from the author. 


\title{
ABSTRACT \\ Preparing for Policy Changes: Social Security Expectations and Pension Scheme Participation*
}

\begin{abstract}
Western governments are currently contemplating how to adapt their Pay-As-You-Go pension systems so that these remain financially sustainable, even with an aged population. To the extent that policy-makers haven't already adapted their old age social security schemes, an ageing population thus leads to policy uncertainty in first pillar pensions. This paper sheds more light on the relationship between public and private savings by analyzing private pension scheme participation in the presence of such policy uncertainty. To do so, I assess the influence of subjective policy change expectations on voluntary pension scheme participation in the Netherlands. I find that participation in private pension schemes is higher for those who assign a high probability to the dismantlement of old age social security - in terms of lower benefits levels but more so in terms of a higher eligibility age. In addition, subjectively short-lived individuals who believe an eligibility age increase to be more likely than a benefit level cut, participate more. This could be explained by the fact that the relative cost of an eligibility age increase is larger for those who expect to live shorter. Individuals hence do prepare themselves for anticipated policy changes in old age social security and policy uncertainty in social security thus seems to lead to an increase in, or crowding in of, private savings.
\end{abstract}

JEL Classification: D84, D91, H55

Keywords: ageing, savings behavior, social security, subjective probabilities, uncertainty

Corresponding author:

Karen van der Wiel

Tilburg University

Department of Econometrics and OR

P.O. Box 90153

5000 LE Tilburg

The Netherlands

E-mail: K.M.vdrWiel@uvt.nl

\footnotetext{
* Thanks to Arthur van Soest, Frederic Vermeulen, James Banks, Rob Alessie, Norma Coe, Katie Carman, and Gema Zamarro for useful comments and suggestions. The Dutch government institution that pays out social security benefits, the Sociale Verzekeringsbank, generously funded this research through Netspar, the Network for Studies on Pensions, Ageing and Retirement.
} 


\section{Introduction}

After several industrialized countries had installed old age social security in the 1940s and 1950s, economists wondered what the effect of these new institutions on private savings would be. A large literature developed that was interested in to what extent public pension schemes crowded out private pension savings. More than fifty years after most Western governments introduced Pay-As-You-Go (PAYG) pension schemes, governments no longer discuss the adornment but rather the demolition of these systems. Particularly the ageing of populations has recently put pressure on policy-makers to cut down on the generosity of their public pension schemes, creating policy uncertainty in first pillar pensions. Therefore, it is now relevant to investigate the response of private savings to a (possible) dismantlement of old age social security. This paper tries to answer this question focusing on potential future changes rather than on changes that are already implemented. Do people sufficiently prepare for the policy changes in PAYG pensions that they anticipate? In addition to discovering more about the relationship between public and private pension schemes, this paper thus also sheds light on individuals' capacity to assess how likely policy alterations are and on their capacity to respond accordingly. Knowing whether their citizens are indeed capable of mitigating the negative effects of these policy changes is essential for all governments, and in particular for those that are currently deciding upon policy changes in their old age social security system.

This paper investigates whether Dutch individuals who anticipate a policy change in old age social security prepare for such a change by participating more often in voluntary pension schemes. First, a model is developed that explains optimal savings behavior in the instance of policy uncertainty in a Pay-As-You-Go (PAYG) pension system. Second, the empirical relationship between subjective expectations regarding two different policy changes and private pension participation is examined for the Netherlands. I find that those who are more convinced of future deteriorations are indeed more likely to participate in a private pension fund. These findings suggest that uncertainty in social security 'crowds in' private pension savings. I define crowding in here as an increase in private savings, in analogy to crowding out which in this context refers to a decrease in private savings due to the installment of old age social security.

In this introduction, I continue by introducing some of the relevant literature. Furthermore, I explain important features of the Dutch pension system. Section 2 then sets out a theoretical model of optimal savings under uncertainty over the future of the old age social security system. Subsequently, Section 3 explains the empirical strategy and includes a description of the data used in the empirical analysis. Section 4 presents the empirical results. Finally, Section 5 concludes and gives some policy advice. 


\subsection{The crowding-in of private savings}

The establishment of old age social security has triggered economists to assess the effect of this important development on wealth accumulation. A relationship between savings and social security was first empirically revealed by Feldstein in 1974. He used aggregate time series to show that social security wealth had halved the rate of private savings in the US. Feldstein argued that consumers had lowered savings because they would be receiving a certain income from PAYG-benefits in retirement.

This 'crowding out' effect of old age social security has since then been addressed by many scholars using both macro- and micro-data sources. Results based on individual information provide weak to strong evidence of crowding out effects in various industrialized countries. See Kotlikoff (1979) for the U.S., Jappelli (1995) and Attanasio and Brugiavini (2003) for Italy, Guariglia and Markose (2000) and Attanasio and Rohwedder (2003) for the U.K. and Alessie, Kapteyn and Klijn (1997), Euwals (2000) and Kapteyn, Alessie and Lusardi (2003) for The Netherlands.

In 1974, when Feldstein published his paper, the outlook on the future of social security was very optimistic, as the following quote indicates.

"The history of social security shows continually rising benefit levels, a fact that individuals no doubt perceive when they contemplate the order of magnitude of their benefits at retirement age." (p. 911)

Since the publication of Feldstein's article, increased awareness of ageing altered this outlook on publicly provided old age pensions in most Western countries. An illustration of this can be found in Dominitz, Manski and Heinz (both 2002 and 2003), who have described expected eligibility for U.S. old age social security using data from the Survey of Economic Expectations (SEE) for 1999 to 2002. They find that a substantial number of respondents believe that the U.S. social security system will collapse entirely within the foreseeable future. In this paper I show that many Dutch individuals are also pessimistic about the future of Dutch old age social security. About one third of respondents in a survey on pension expectations (the 'Pensioenbarometer') assigns a probability higher than .5 to a ten percent decrease in the level of benefits within the next twenty years. Respondents are even more convinced that the old age social security eligibility age will change within twenty years. More than half of them assign a probability higher than .5 to a two year increase in the eligibility age.

Taking these expectations into account, this paper investigates the crowding in effect of uncertainty in social security on private savings. The crowding in term refers to increases in private wealth because of a possible dismantlement of the social security system in analogy to Martin Feldstein's crowding out effect. To my knowledge, the effects of a potential degeneration 
of the social security system on wealth accumulation has not been assessed so far.

\subsection{Expectations measured in subjective probabilities}

In the empirical analysis in this paper I analyze the response to expectations by exploiting variation in the subjective probabilities individuals assign to policy changes. The analysis of explicit subjective expectations is a popular new field of research in economics. Manski (2004) provides an overview of the use of subjective probabilities in modern economics. Individuals seem surprisingly able to translate their knowledge on the idiosyncratic risk they face into a probability that is equal to the ex-post realized probability. For example, Hurd and McGarry (2002) find that elderly who die within two years of participating in the Health and Retirement Study (HRS) had reported a much smaller probability of surviving until the age of 75 than those who actually survived.

The predictive power of subjective survival probabilities will be exploited in the empirical analysis of this paper. More importantly, subjective probabilities concerning the future occurrence of a change in the social security system will be the independent variables of interest.

The relationship between subjective expectations and individual savings behavior is analyzed by authors such as Guiso, Jappelli and Terlizzese (1992) and Stephens (2004). Guiso et al. use a subjective measure of income uncertainty in order to quantify the size of precautionary savings and in doing so they discover a substantial size of precautionary savings. Stephens examines whether job loss expectations affect savings behavior and does not find any effect. He argues this could be because of probability weighting in a loss aversion context (see Bowman et al., 1999) so that individuals with very small job loss probabilities actually over-weight these.

\subsection{Old age social security in The Netherlands}

The Netherlands has a hybrid pension system. All three traditional pillars - the mandatory public pillar, the mandatory occupational pillar and the voluntary private pillar - are of considerable importance in providing an income for the elderly when compared to other countries (see Boersch-Supan, 2004 for more information). The first pillar has a Pay-As-You-Go character, while the second and third pillar are capital funded.

Most employees are obliged to participate in the second pillar, the occupational pension schemes. Annuitization of their assets is compulsory and there is little freedom over the investment choices. The most common third pillar pension products are the so-called 'lijfrente-polissen' and 'koopsompolissen'. Consumers can buy these annuities from banks and insurers either through regular contributions (lijfrente) or through the deposit of a lump- 
sum (koopsom). Contributions to second and third pillar pensions schemes are to a certain degree tax-deductible.

The old age social security arrangement in the Netherlands, the $A l$ gemene Ouderdomswet (AOW), was established in 1957 to provide a base pension for all inhabitants. Designed on Beveridge's principle, the eligibility for and level of AOW benefits does not depend on contributions paid, income or wealth, only on years of residence in the Netherlands. For each year one has legally resided in The Netherlands between the ages of 15 and 65 , one receives two percent of the maximum AOW amount from the age of 65 onwards, irrespective of retirement. The real level of AOW benefits has remained stable since 1979, at approximately seventy percent of the minimum wage. The net level of a couple's combined AOW benefits equals the net minimum wage. In 2007, this came down to a gross monthly allowance of EUR 945 for singles and EUR 648 for pensioners with a partner. ${ }^{1}$

Ageing as well as changing economic and political circumstances triggered discussions on the sustainability of PAYG-pensions from the late 1970s onwards. The historical Dutch policy debate is summarized by Van Eekelen (2006). Despite this debate the old age social security arrangement has remained roughly the same as it was when introduced in 1957.

The fact that the PAYG-system is so universal, i.e. each individual in principle receives the same benefits, provides a great research environment. The expectations individuals form over the future of the system thus all relate to the exact same thing and are not confounded by idiosyncratic risk factors. In contrast, the expectations regarding eligibility for U.S. social security reported in Dominitz et al. (2003) combine expectations about macro (such as policy uncertainty) and micro risks (such as unexpected income shocks).

\section{Theoretical model}

In this section I present a simple theoretical model on how the savings behavior of expected utility maximizers would respond to their expectations regarding the future of a first pillar pension system. The life-cycle model developed here is a three-period model of consumption. All individuals live for three periods. Individuals just face two decisions in their life; what to save in the first period $\left(S_{i}\right)$ and what to consume out of these savings in the second period $\left(z_{i}\right)$.

Labor supply and retirement are thus exogenous. I realize that this

\footnotetext{
${ }^{1}$ The system is financed through an earmarked payroll tax, which constitutes $17.9 \%$ on the first EUR 30,000 of gross income. Those over 64 do not pay this tax as they are already receiving benefits. In 1997 the AOW tax rate was legally capped so that the remainder of AOW expenditures are now financed through general taxes which are also paid by retirees with a substantial pension income. Whereas in 2001 still all expenditures were financed through the payroll tax, in 2006 this decreased to $70 \%$ of AOW expenditures.
} 
assumption is a great simplification of reality, but endogenous retirement would not greatly change my results ${ }^{2}$. In the first period everybody is young and working. Workers receive individual-specific wages $\left(I_{i}\right)$, which are larger than one for everyone. All individuals are retired in period two and three. I assume a standard additive model as in Browning and Lusardi (1996) that allows for a precautionary savings motive, as I believe this provides the clearest, yet most plausible results. Lifetime utility is therefore additive and has a logarithmic functional form.

There exists a government that pays out a fixed old age social security benefit $(P)$ to all citizens. The government raises both a general consumption $\operatorname{tax} \tau$ and an additional consumption $\operatorname{tax} \theta$ that equals the contribution to the old age social security system. I choose a consumption tax in order to mirror the tax-deductible nature of pension savings. Individuals that receive a pension benefit do not contribute to the pension system, although they do pay general taxes. Hence, there is a Pay-As-You-Go pension system in place. Note that the PAYG system is not necessarily actuarially fair as I assume there exists a financial fund that gathers the excess contributions in certain periods and that pays the benefit deficits in other periods. For simplicity, it is impossible to leave a bequest in the model and the market interest rate and the discount rate offset each other. Like in the real world, individuals cannot borrow against future old age social security benefits so first period savings should be equal to or exceed zero $\left(S_{i} \geq 0\right)$.

In the status quo, policy option A, the government pays out the PAYG benefit of level $\mathrm{P}$ to all citizens in both periods two and three. The utility functions for all three periods in the status quo are displayed in the equations below.

$$
\begin{aligned}
& u_{1}^{A}=\ln \left((1-(\tau+\theta))\left(I_{i}-S_{i}\right)\right) \\
& u_{2}^{A}=\ln \left((1-\tau)\left(z_{i}+P\right)\right) \\
& u_{3}^{A}=\ln \left((1-\tau)\left(S_{i}-z_{i}+P\right)\right)
\end{aligned}
$$

Note that in a deterministic world the lifetime utility maximization problem can be solved using backward induction; first maximizing over $z_{i}$ than over $S_{i}$. For expositional reasons I will therefore only show the second step maximization problem over first period savings in the remainder of this section.

One could think of the government's financial fund running out of money because of persistently shrinking generations. At first, the status quo might be maintained as governments can easily borrow on the credit market. After

\footnotetext{
${ }^{2}$ If labor supply is modeled as a function of potential income and the disutility experienced from working and if labor demand is modeled as a function of workers' productivity, the retirement age should be the same under all three policy options.
} 
some time though, policy-makers could respond to the ageing of the population by adapting the PAYG pension scheme. The government could then choose one of the following alternative policy options.

- Option B: providing a lower benefit. Individuals will receive a benefit of $(1-\lambda) P$, for $0<\lambda<1$.

- Option C: only providing benefits in period three. The government will shift the eligibility age upwards: it will only provide benefits of the original level $P$ in the third period, but not in the second.

As the government is free to decide upon an alternative PAYG-policy, I consider savings in a stochastic world. Hence, individuals choose an optimal savings level $\left(S_{i}\right)$ in the first period under uncertainty over the state of the world in the second and third period. The government decides on a policy option after the first period and this decision is carried out and publicly known in period two and period three. It seems realistic to assume that the government will not change any policy rules for those who are already retired (i.e. between period two and three).

In their first period maximization problem consumers then maximize utility over savings taking into account the probabilities they individually assign to the future occurrence of the different policy options. As each individual is one of many I assume that each individual can be seen as a 'system-taker' (think of a price-taker). This means that the subjective probabilities a single individual assigns to different policy options do not influence the actual choice of the government.

$$
\begin{aligned}
P(\text { Option A: Status quo }) & =\alpha_{i} \\
P(\text { Option B: Lower benefits }) & =\beta_{i} \\
P(\text { Option C: Later benefits }) & =\delta_{i}
\end{aligned}
$$

First, I analyze uncertainty about the two possible policy changes separately. So, individuals consider only two possible states of the world; One is the status quo (policy option A) and the other is a significant policy change, either lower benefits (B) or later benefits (C). When there is only uncertainty between policy options $\mathrm{A}$ and $\mathrm{B}$, the maximization problem can be found below. Note that I assume that $\alpha_{i}$ and $\beta_{i}$ add up to one in this case.

$$
\begin{aligned}
\max _{S_{i}} \ln \left((1-(\tau+\theta))\left(I_{i}-S_{i}\right)\right) & +2\left(1-\beta_{i}\right) \ln \left((1-\tau)\left(\frac{1}{2} S_{i}+P\right)\right) \\
+ & 2 \beta_{i} \ln \left((1-\tau)\left(\frac{1}{2} S_{i}+(1-\lambda) P\right)\right)
\end{aligned}
$$

The algebraic solution to this maximization problem can be found in appendix A and involves many terms which are difficult to interpret at first sight. For clarification, I therefore draw a 3D image of optimal savings with 
the probability an individual assigns to lower benefits $\left(\beta_{i}\right)$ on the $\mathrm{x}$-axis and the cut in the benefit level $(\lambda)$ on the z-axis in figure 1 . The value of the benefit level, $\mathrm{P}$, is normalized to one here and income is set to twice the benefit level.

The figure presents intuitive results, such that if the cut in benefit levels

Figure 1: Optimal savings when there is uncertainty between the status quo and lower benefits (option B), for different levels of $\beta_{i}$ and $\lambda$.

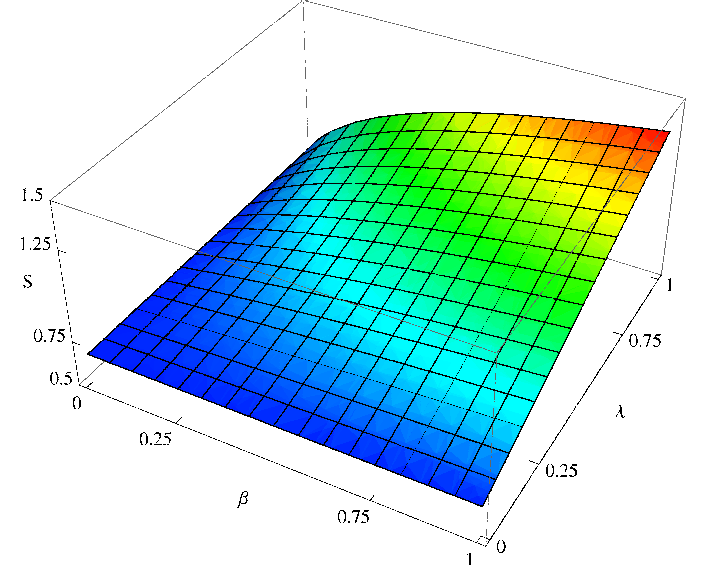

is negligible (i.e. zero) the probability an individual assigns to policy option B doesn't affect the savings level. Similarly, if someone doesn't assign any positive value to lower benefit levels coming into effect, the actual size of the cut has no influence on savings. For any positive level of $\lambda$ however, savings are increasing in $\beta_{i}$, the probability one assigns to lower benefits. Correspondingly, for any positive level of $\beta_{i}$, savings are increasing in $\lambda$, the potential cut in benefits.

When there is only uncertainty between policy options A, the status quo, and $\mathrm{C}$, an increase in the eligibility age, the maximization problem can be found below. Note that I now assume that the sum of $\alpha_{i}$ and $\delta_{i}$ is equal to one so that potential changes to the benefits level are ignored.

$$
\begin{array}{r}
\max _{S_{i}, z_{i}} \ln \left((1-(\tau+\theta))\left(I_{i}-S_{i}\right)\right)+2\left(1-\delta_{i}\right) \ln \left((1-\tau)\left(\frac{1}{2} S_{i}+P\right)\right) \\
+2 \delta_{i} \ln \left((1-\tau)\left(\frac{1}{2}\left(S_{i}+P\right)\right)\right)
\end{array}
$$

The analytical solution to this problem is somewhat simpler than in the previous situation and can be found in Appendix A. Figure 2 graphically represents optimal saving under uncertainty over the status quo and later benefits, depicting the probability assigned to later benefits, $\delta_{i}$, on the xaxis. The graph, that has income fixed at twice the benefit level again, is very straightforward. The higher the probability individuals assign to a shift 
in the social security eligibility age, the higher are optimal savings.

So, not surprisingly, assigning a positive probability to any ageing-

Figure 2: Optimal savings when there is uncertainty between the status quo and later benefits (option C), for different levels of $\delta_{i}$.

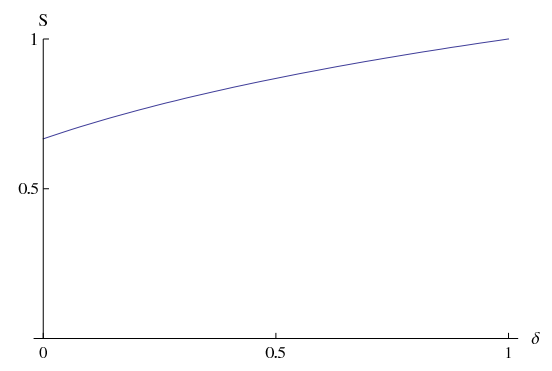

induced policy change in old age social security should lead to higher savings. This phenomenon could be called crowding in, the opposite of crowding out as introduced by Feldstein (1974).

From now on, I will consider the situation in which the status quo is no longer sustainable. I will hence analyze saving in a world that inhibits uncertainty over which of the two alternative policy options the government will choose, lower benefits (option B) or later benefits (option C). I therefore define $\gamma_{i}$ here as $\frac{\delta_{i}}{\beta_{i}+\delta_{i}}$, so as the ratio of the later benefit expectations over the sum of the lower and later benefits expectations. Note that this is necessary in the model as $\beta_{i}$ and $\delta_{i}$ can add up to more than one. The pertaining maximization problem is represented by the equation below.

$$
\begin{array}{r}
\max _{S_{i}, z_{i}} \ln \left((1-(\tau+\theta))\left(I_{i}-S_{i}\right)\right)+2\left(1-\gamma_{i}\right) \ln \left((1-\tau)\left(\frac{1}{2} S_{i}+(1-\lambda) P\right)\right) \\
+2 \gamma_{i} \ln \left((1-\tau)\left(\frac{1}{2}\left(S_{i}+P\right)\right)\right)
\end{array}
$$

As before, I do not present the algebraic solution (which can be found in Appendix A), but I present optimal savings graphically in figure 3. This graph shows $\gamma_{i}$, the ratio of later benefit expectations over the total expectations of any policy change, on the $\mathrm{x}$-axis and $\lambda$, the cut in the benefit-level in case of lower benefits, on the z-axis.

Figure 3 uncovers an interesting pattern. The relationship between savings and the parameter $\gamma_{i}$ reverses as the benefit cut gets larger. For low cuts $(\lambda<0.5)$, savings increase in $\gamma_{i}$, as the loss associated with only benefits in the third period is larger than the loss associated with lower benefits. For high cuts however $(\lambda>0.5)$, savings actually increase in $\gamma_{i}$, as the loss associated with later benefits is now smaller than the loss associated with lower benefits. 
Figure 3: Optimal savings when there is uncertainty between lower benefits (option B) and later benefits (option C), for different levels of $\gamma_{i}$ and $\lambda_{i}$.

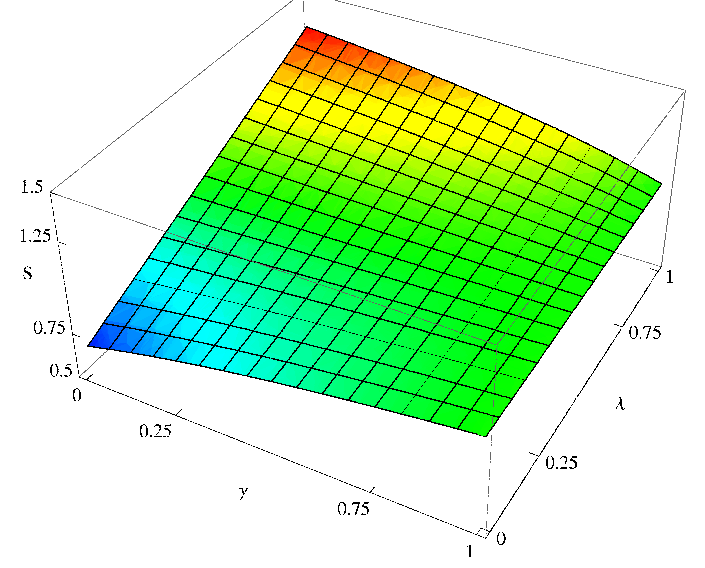

I now continue to analyze the situation in which the government will definitely change the social security system, so that there is only uncertainty between policy option B and C. I will argue that the level of private pension savings also depends on the interaction between $\gamma_{i}$ - which policy change a person believes is more likely - and her life expectancy. In order to do so I personalize the parameter for the cut in benefit levels $\left(\lambda_{i}\right)$ to represent differences in the relative individual loss associated with lower (option B) or later (option $\mathrm{C}$ ) benefits. The idea is that in real-life different survival probabilities render the loss associated with lower and later benefits different across individuals. For example, someone who is certain to die between the age of 65 and 67 is likely to associate a larger loss to a two year increase in the old age benefits eligibility age than to a ten percent cut in the benefits level. Someone who is certain to die between the age of 95 and 100 will instead be more concerned with a ten percent benefit level cut.

To illustrate this further figure 4 depicts optimal savings for two groups of individuals: the 'long-lived' and the 'short-lived'. Up to now I have assumed that everybody survives up until the end of the third period. This will still hold for the long-lived individuals, but a new group of people is introduced who know themselves that they will die by the end of the second period. I assume that the government has no way of differentiating between people in terms of the social security benefit. The long-lived group will therefore receive later benefits with probability $\gamma_{i}$, while the short-lived group will receive no benefit at all with the same probability. Both groups will receive a benefit of level $\left(1-\lambda_{i}\right) * P$ with the probability $\left(1-\gamma_{i}\right)$. The algebraic optimal savings for the short lived can be found in the appendix. For simplicity, figure 4 includes results for a $\lambda$ equal to 0.40 , which corresponds roughly to a real-life cut in benefit levels of ten percent relative to a two-year increase in the eligibility age. 
Figure 4: Long-lived and short-lived individuals: Optimal savings when there is uncertainty between lower benefits and later benefits for different levels of $\gamma_{i}\left(\lambda=\mathrm{S}_{\mathrm{S}} .4\right)$.

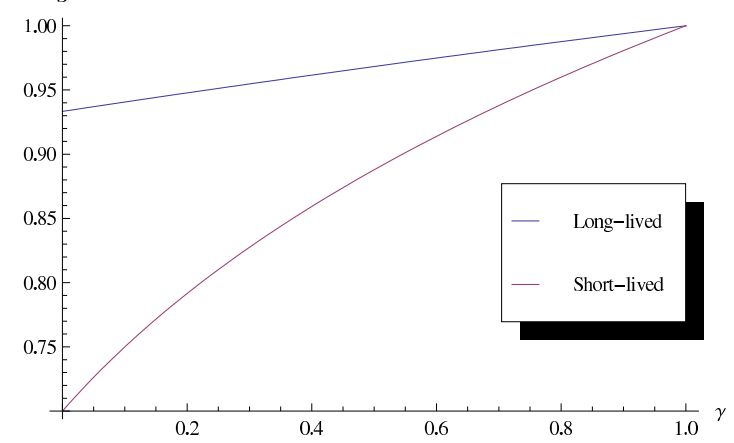

Figure 4 shows that savings for the short-lived are much more sensitive to their subjective expectation $\gamma_{i}$, representing the relative likelihood of an increase in the social security eligibility age over a decrease in benefit levels. It can be shown that this difference is larger for higher levels of the benefit cut, $\lambda$.

In the empirical analysis I will hence have three strong hypotheses to test: a) Private savings, and hence participation in a private pension scheme, are increasing in the subjective probability individuals assign to lower benefits, $\beta_{i}$. b) Private savings, and participation in a private pension scheme, are also increasing in the subjective probability individuals assign to an increase in the eligibility age, $\delta_{i}$. c) Private savings, and thus participation in a private pension scheme, are increasing in the relative 'fear' for later benefits (over the sum of lower and later benefits) for short-lived individuals, that assign themselves a relatively low survival probability. To test these three hypotheses separately, I will test the three theoretical uncertainty models separately in Section 4 of this paper. The model in which there is uncertainty between lower and later benefits will be estimated given the sum of uncertainty about abandoning the status quo. An additional set of models will be estimated including interactions between the expectation parameters and the subjective probabilities individuals assign to their own survival.

\section{Empirical strategy and data}

\subsection{Empirical strategy}

The relationship between policy change expectations and pension fund participation will be tested in a reduced form. Eight linear single regression models are estimated of voluntary participation in a pension scheme. These models all include one or multiple of the expectation parameters $\beta_{i}$, the probability that benefits will be lowered, $\delta_{i}$, the probability that the social 
security eligibility age will increase and $\gamma_{i}$, the ratio of $\delta_{i}$ over the sum of $\beta_{i}$ and $\delta_{i}$. The dependent variable, participation in a voluntary pension scheme, is discrete and therefore I am estimating standard probits. Error terms are clustered at the individual level. The first four estimated models, 1a to $4 \mathrm{a}$, can be found in the equations below. The last four estimated models, $1 \mathrm{~b}$ to $4 \mathrm{~b}$, are identical to their respective a-versions but moreover include interactions of the expectations with a dummy for being subjectively short-lived.

$$
\begin{aligned}
y_{i}^{*} & =\zeta_{\beta 1} * \beta_{i}+x_{i}^{\prime} \zeta+\epsilon_{i}(1 \mathrm{a}) \\
y_{i}^{*} & =\zeta_{\delta 1} * \delta_{i}+x_{i}^{\prime} \zeta+\epsilon_{i}(2 \mathrm{a}) \\
y_{i}^{*} & =\zeta_{\gamma 1} * \gamma_{i}+\zeta_{\text {sum }} *\left(\beta_{i}+\delta_{i}\right)+x_{i}^{\prime} \zeta+\epsilon_{i}(3 \mathrm{a}) \\
y_{i}^{*} & =\zeta_{\beta 1} * \beta_{i}+\zeta_{\gamma 1} * \gamma_{i}+x_{i}^{\prime} \zeta+\epsilon_{i}(4 \mathrm{a})
\end{aligned}
$$

The identification of the expectation coefficients (the $\zeta_{\beta}$ 's, $\zeta_{\delta}$ 's and $\zeta_{\gamma}$ 's) comes from the heterogeneity in expectations among individuals. In order to be able to apply this identification strategy I have to make an assumption about what process generates this heterogeneity. This is not a-priori clear since the event respondents are evaluating is the exact same for all and hence one could expect similar probability answers for all respondents. A natural explanation for the dispersion in answers is that individuals exhibit different information search intensities and apply different information processing technologies. If this is the case, my identification strategy is justified, providing that I am willing to assume that in the savings regressions the political information handling characteristics do not play a role in the error term. Said differently, I can apply this strategy if I believe that apart from the policy change expectations and the various demographic controls, the political information handling characteristics don't seriously influence pension scheme participation. One could however also argue that differences in general pessimism drive the dispersion in expectations. Although I cannot rule out that some of the heterogeneity involves general pessimism, I don't believe this captures all variation. My argument is that if pessimism was driving everything, I shouldn't find any results in the empirical models including the ratio of different policy change expectations. Pessimism should after all affect the two policy expectations similarly. Nevertheless, I do find significant results for the $\zeta_{\gamma}$-coefficient in tables 2 and 3 . In this paper I will therefore conclude that the heterogeneity in policy expectations reflects differences in information search intensities and information processing technologies. I furthermore assume that these information handling characteristics don't play a separate major role in the pension scheme participation decision. 


\subsection{Data}

For the empirical analysis I use data from the Dutch Central Bank Households Savings Survey (DHS), waves 2003 up to $2007^{3}$ combined with data from the Dutch Pensionbarometer, waves May 2006 up to May 2008. These datasets are both collected by Tilburg University's CentERdata; the first in cooperation with the Dutch Central Bank and the latter in cooperation with Netspar, a Network for Studies on Pensions, Ageing and Retirement. Both datasets are enumerated through the same Internet panel. Much is done to prevent selection effects. The respondents are randomly selected from the general municipalities' administration and when a chosen individual does not have access to the Internet, access is provided. The surveys enumerate partly overlapping subsets of a large pool of respondents so that the datasets could be merged on the identification number of individuals. The information about pension scheme participation and all independent variables except for the expectations are taken from the Dutch Central Bank Households Savings Survey. This survey is designed to shed more light on (the reasoning behind) savings decisions and enumerates approximately 3000 households each year. The subjective expectations were taken from the Pensionbarometer which is collected mainly to produce longitudinal statistics for confidence levels in the Dutch pension system. Every month on average 500 respondents receive the digital questionnaire although every respondent only receives the questions once every three months. This batch system was introduced to be able to produce the confidence statistics regularly, but not to overwhelm the respondents with questions. In this paper, I use the first twenty-four waves of the Pensionbarometer of which the last was enumerated in April 2008. A total of 2,554 individuals were interviewed. I limit my sample to those individuals between the ages of 30 and 59 who are participating in a mandatory occupational pension scheme and who have participated in the Pensionbarometer more than once. As a result of the merge and my selection, my sample consists of 3,228 observations and 1,114 individuals.

The dependent variable in my analysis is a dummy on voluntary pension scheme participation. The information for this variable is taken from several binary questions in the DHS that ask about voluntary pension scheme contributions each year. An example of such a question is "Did you contribute to a 'lijfrente' pension scheme?". Although there is no specific time horizon mentioned in this question, respondents seem to interpret it as relating to a finite time period such as a year. Evidence for this is found in the transition probabilities from one survey to the next: nineteen percent of my sample switch from having contributed to a 'lijfrente' to not having contributed whereas this would be impossible if respondents would interpret the ques-

\footnotetext{
${ }^{3}$ Earlier years of the DHS are available but not included as no subjective survival probabilities were administered before 2003.
} 
Table 1: Percentage of full sample participating in voluntary pension asset types $(\mathrm{N}=3,228)$

\begin{tabular}{|l||c|c|c|c|c|}
\hline Asset type & 2003 & 2004 & 2005 & 2006 & 2007 \\
\hline \hline 3rd pillar - 'lijfrente' & $31 \%$ & $33 \%$ & $32 \%$ & $30 \%$ & $26 \%$ \\
\hline 3rd pillar - 'koopsom' & $9 \%$ & $11 \%$ & $12 \%$ & $10 \%$ & $10 \%$ \\
\hline 2nd pillar - extra entitlements & $1 \%$ & $2 \%$ & $1 \%$ & $2 \%$ & $1 \%$ \\
\hline 2nd pillar - extra payments & $2 \%$ & $2 \%$ & $1 \%$ & $1 \%$ & $1 \%$ \\
\hline One of the above & $38 \%$ & $42 \%$ & $42 \%$ & $38 \%$ & $35 \%$ \\
\hline \hline $\mathrm{N}$ & 500 & 617 & 697 & 695 & 719 \\
\hline
\end{tabular}

tion as ever having contributed. The dummy in the regressions summarizes whether someone contributed to one designated third pillar pension accounts and/or whether someone voluntary contributed more than they were obliged to to their occupational pension fund. I have taken this variable as the most indicative of one's intention to save voluntarily for old age. As could be already understood from the introduction, most Dutch employees are obliged to participate in occupational pension schemes and total pension wealth is therefore not necessarily a reflection of individual savings decisions. Unfortunately, I do not have detailed information on the level of contributions made into the voluntary (nor the mandatory) pension schemes each year.

Table 1 presents the number of respondents in my sample participating in any of these asset schemes per survey year. The variable in the bottom row, whether an individual owns any of the asset types above, is used in the regressions. The most popular voluntary pension savings product is a so-called 'lijfrente-polis', a private pension product that requires regular contributions. The second most popular pension product is the 'koopsompolis', a private savings account that is like the 'lijfrente-polis' to a certain degree tax-exempt, but that requires a lump-sum contribution. Overall, about forty percent of my sample owns at least one type of designated voluntary pension assets. Older individuals (46\%) and richer individuals (49 $\%$ ) contribute more often to pension schemes, but young individuals (32 $\%)$ and low income individuals $(27 \%)$ still contribute to a relatively large extent.

The most important independent variables in my analysis are those that represent the policy change expectations, $\beta_{i}$ and $\delta_{i}$. The variables are based on subjective probability answers taken from the Pensionbarometer collected by Tilburg University's CentERdata. Every three months respondents are faced with the following two questions; "What probability (between 0.0 and 1.0) do you assign to at least ten percent lower real AOW-benefits within twenty years" and "What probability (between 0.0 and 1.0) do you assign to an at least two year higher AOW-eligibility age within twenty 
years". As it is unlikely that consumers will change their pension plans every three months according to their updated social security beliefs, I am interested in a relatively stable measure of policy expectations. Therefore I use the individual means of the assigned probabilities over the observed 24 monthly waves as my measures for $\beta_{i}$ and $\delta_{i}$. Note that this implies that $\beta_{i}, \delta_{i}$ and $\gamma_{i}$ are time-invariant in my dataset. In order to be able to merge the expectations variables (surveyed in 2006-2008) to the pension scheme information (surveyed in 2003-2007) I moreover have to make the assumption that individuals' relative expectations have remained stable over time. Given that in the period 2003 to 2008 the Dutch old age social security system didn't change in any way, I conclude that the assumption about a stable distribution of expectations over these six years is plausible.

Histograms of the $\beta_{i}$ (lower benefits probability) and $\delta_{i}$ (later benefits probability) variables are found in figure 5 and figure 6 respectively. It can be seen that the mode of $\beta_{i}$ is lower than that of $\delta_{i}$, suggesting that in general individuals believe that an increase in the eligibility age is the most likely policy change. This is confirmed when checking the average expectations (0.42 with s.d. .24 and 0.53 with s.d. .24).

Figure 7 displays a histogram of $\gamma_{i}$, the ratio of the estimates of $\delta_{i}$ (later

Figure 5: Histogram for the probability of lower benefits within twenty years, $\beta_{i}(\mathrm{~N}=3,228)$

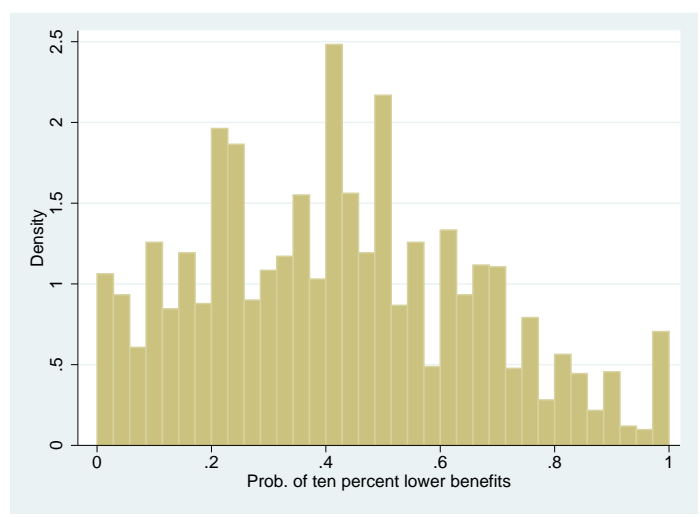

benefits probability) over the sum of $\beta_{i}$ (lower benefits probability) and $\delta_{i}$. About $34 \%$ of individuals assign an equal probability to both policy changes, but the majority of individuals believes one of the two is more likely to occur with a larger group considering the eligibility age increase more likely. The correlation-coefficient of $\beta_{i}$ and $\delta_{i}$ actually is equal to 0.5 .

Another important independent variable in the empirical analysis is the respondent's life expectancy, proxied by a dummy on whether someone is subjectively short-lived. This variable is constructed from of a question posed in the Dutch Central Bank Household Savings Survey that asks "What 
Figure 6: Histogram for the probability of later benefits within twenty years, $\delta_{i}(\mathrm{~N}=3,228)$

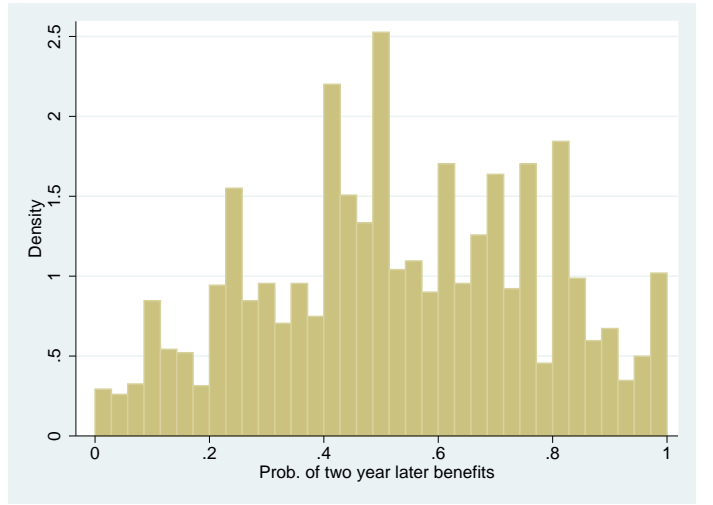

is the probability - between 1 and 10, that you will survive up until the age of 75?". A histogram of answers to this question can be found in the appendix (figure A-1). The unconditional mean of and median of the survival probability are equal to seven, the mode is equal to eight. In order to construct the short-lived dummy I first calculate average probabilities per age and gender group. A graph of these average probabilities can be seen in the appendix (graph A-2). The short-lived dummy is then equal to one if an individual reports a lower probability than the average of his or her appropriate birth year and gender group. A binary variable was chosen to render the estimation results easy to interpret. This means that $39 \%$ of my sample is classified as short-lived. Other controls in the pension fund participation regressions include log gross income, education level, age, a partner dummy, a child dummy and year dummies. Descriptive statistics for six different sub-samples can be found in the appendix (tables A-1 and A-2). 
Figure 7: Histogram of $\gamma_{i}$ (the ratio of the estimates of $\beta_{i}$ (lower benefits probability) over the sum of $\beta_{i}$ and $\delta_{i}$ (later benefits probability)) in my sample $(\mathrm{N}=3,228)$

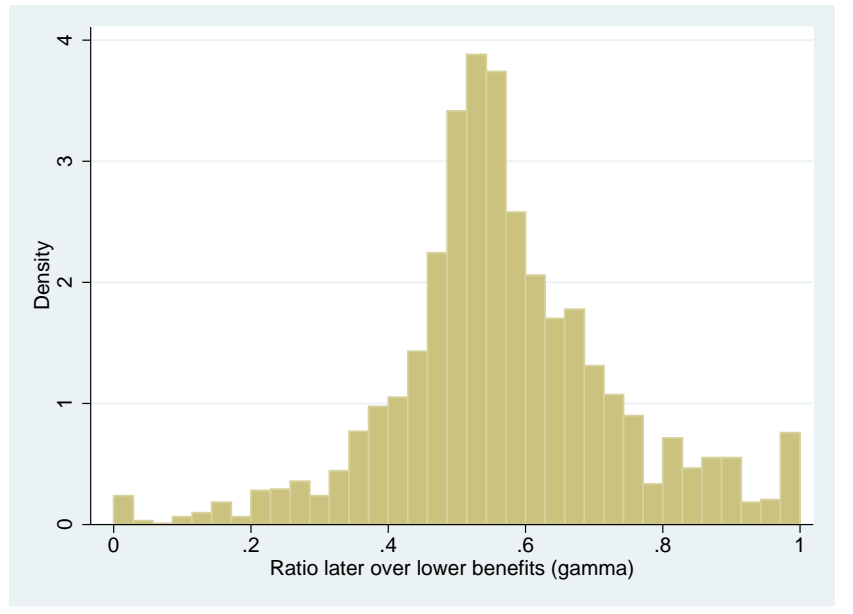

\section{Empirical results}

This section discusses the results of the empirical analysis. Table 2 displays the relevant coefficients of all eight probit regressions of participation in a voluntary pension scheme. The appendix contains a table of standard errors (table A-3). The Akaike's information criteria of these models can be found in table 4. All eight models are estimated on four different samples; the total sample (column I), the young sample - those between 30 and 39 (column II), a middle aged sample - those between 40 and 49 (column III) and a relatively old sample - those between 50 and 59 (column IV). This was done as there is reason to believe that the degree to which individuals prepare for a policy change in old age social security is different across ages. One could for example argue that the larger the number of years to retirement, the weaker the incentive is to act upon current policy change expectations. Table 2 certainly confirms this notion. Later on in this section the same exercise will be done for three different income groups.

The coefficients for the first three models in the first column estimated on the entire sample, in which one type of uncertainty is investigated at a time, illustrate that individuals who assign high policy change probabilities participate more in voluntary pension schemes. This is in accordance with the first two hypotheses of Section 2. It seems that the second model in which there is only policy uncertainty between the status quo and an increase in the social security eligibility age explains most variation in the data. This conclusion can however not be drawn for all age groups. The young react most to their relative 'fear' for a higher eligibility age $\left(\gamma_{i}\right)$, the middle age category reacts very strongly to their higher eligibility age ex- 
Table 2: Coefficients of probit models. Dependent: participation in voluntary pension scheme. Low age: 30-39 years, Middle age: 40-49 years, High age: 50-59 years. Interactions are with the short-lived dummy.

\begin{tabular}{|ll|c|ccc|}
\hline Model & Variable & $(\mathrm{I})$ & $(\mathrm{II})$ & $(\mathrm{III})$ & $(\mathrm{IV})$ \\
\hline & & All & Low age & Middle age & High age \\
\hline \hline 1a & Beta & 0.241 & -0.075 & 0.301 & 0.446 \\
\hline 2a & Delta & $0.507^{* *}$ & 0.104 & $1.139^{* * *}$ & 0.443 \\
\hline 3a & Gamma & 0.078 & 0.263 & $0.809^{*}$ & -0.319 \\
& Sum & $0.269^{* *}$ & 0.022 & $0.572^{* * *}$ & $0.307^{*}$ \\
\hline 1b & Beta & $0.481^{*}$ & -0.171 & $0.688^{*}$ & $0.782^{*}$ \\
& Interaction & $-0.619^{*}$ & 0.248 & $-0.992^{*}$ & $-0.895^{*}$ \\
& Short-lived & 0.090 & -0.27 & 0.247 & 0.203 \\
\hline 2b & Delta & 0.339 & -0.042 & $1.213^{* * *}$ & 0.127 \\
& Interaction & 0.454 & 0.402 & -0.193 & $0.875^{*}$ \\
& Short-lived & $-0.414^{*}$ & -0.386 & -0.043 & $-0.610^{*}$ \\
\hline 3b & Gamma & -0.315 & 0.150 & 0.572 & $-0.952^{*}$ \\
& Interaction & $1.067^{*}$ & 0.343 & 0.611 & $1.694^{* *}$ \\
& Sum & $0.265^{* *}$ & 0.021 & $0.573^{* * *}$ & 0.285 \\
& Short-lived & $-0.778^{* *}$ & -0.35 & -0.499 & $-1.132^{* *}$ \\
\hline 4a & Beta & 0.033 & -0.162 & -0.148 & 0.306 \\
& Delta & $0.464^{* *}$ & 0.183 & $1.200^{* * *}$ & 0.329 \\
\hline 4b & Beta & 0.411 & -0.196 & 0.256 & $0.866^{* *}$ \\
& Interaction & $-1.013^{* * *}$ & 0.066 & $-1.040^{*}$ & $-1.600^{* *}$ \\
& Delta & 0.168 & 0.049 & $1.107^{* *}$ & -0.204 \\
& Interaction & $0.899^{* *}$ & 0.381 & 0.223 & $1.527^{* *}$ \\
& Short-lived & -0.221 & -0.398 & 0.179 & -0.313 \\
\hline \hline N & & 3228 & 931 & 1097 & 1198 \\
Ind & & 1114 & 414 & 422 & 439 \\
\hline
\end{tabular}

${ }^{*} p<0.05,{ }^{* *} p<0.01,{ }^{* * *} p<0.001$

Standard errors are clustered at the individual level (table A-3)

All regressions include the short-lived dummy, a constant, log income, education level, age, a child dummy, a partner dummy and year dummies. 
pectations $\left(\delta_{i}\right)$, whereas the oldest age group responds most to their lower benefit level expectations $\left(\beta_{i}\right)$. The middle age category apparently drives the effects in the overall sample as this group displays the strongest reaction to its policy change expectations. The young on the other hand don't significantly prepare for the anticipated policy changes.

The models five, six and seven furthermore include an interaction term between the expectations variables and a dummy for being subjectively short-lived (see Section 3 for an explanation of this dummy). In model five, where only uncertainty in the level of benefits is considered, the interaction effect in the total sample is significant and negative, undoing the positive effect of the change probability for the short-lived. Only individuals who believe they have a good chance of being around at age 75 thus prepare for a possible decrease in social security levels. This effect is clear for those older than 39, but is not present for younger individuals. In model six, where only uncertainty in the eligibility age is considered, the interaction effect in the entire sample is positive, so that short-lived individuals react more to their eligibility age expectations. The coefficient is however not significant as the interaction has an opposite sign for the middle-aged group. Short-lived individuals between 50 and 59 do significantly let their voluntary pension scheme contribution depend on their $\delta_{i}$. Focusing on the total sample coefficients in the seventh model, the interaction between being short-lived and the relative 'fear' for an eligibility age increase is large, positive and significant, exactly as my theoretical model predicts. In the model I explain that the expected cost of a higher eligibility age is relatively larger than the cost of lower benefits for individuals that expect to live shorter than others. The empirical effect is clearly driven by the oldest age group, probably because the subjective survival probabilities for this group contain most information.

In model four, both policy change expectations are included without the interactions, which takes away some of the effect of lower benefit expectations. However, pension scheme participation is still significantly affected by the probability that the social security eligibility age will go up. Also in this model, the middle age group reacts most distinctly and those under forty hardly react at all. In model eight, both policy change expectations are included as well as the interactions, and the results from models five, six and seven are replicated. The two interactions are both highly significant in the total sample model. Conditioning on the later benefit expectations, shortlived individuals that assign a high probability to lower benefits participate less in pension schemes. Conditioning on the lower benefit expectations, short-lived individuals participate more in pension schemes when they believe a higher eligibility age is likely. When considering the results for the young sample only, it becomes clear that individuals between 30 and 39 don't really prepare for a policy change. Retirement is apparently too far away for this group to take current policy change expectations into account when 
purchasing pension products. The older two age categories do significantly prepare for policy changes and the interaction effects of being short-lived are most important for the oldest group.

Age is not the only demographic characteristic that is used to divide the sample to estimate the eight models separately. In the last three columns of table 3 the sample is split in three equal income categories to investigate how different income groups react to policy change expectations. There is reason to believe that responses will be different because the Dutch old age social security benefit levels are equal for all (see Section 1.3) so that concavity of the utility function could lead to a smaller response to policy change expectations for richer individuals. Column V displays results for low income-individuals - those who earn less than EUR 25,150 a year -, column VI shows coefficients for middle-income individuals - those with a gross yearly income between EUR 25,150 and EUR 38,100 - and the estimates in column VII use information of high income individuals - those with a gross yearly income over EUR 38,100. The appendix contains a table of standard errors (table A-4) associated to the displayed coefficients. The Akaike's information criteria of these models can be found in table 4 . It turns out that responses indeed vary. Broadly speaking, rich individuals indeed do not care so much about upcoming policy changes. The level of social security benefits relative to their own income probably doesn't justify any additional action if old age benefits might be affected. Middle-income individuals respond much more to their policy change expectations. In particular, the eligibility age expectations explain a substantial degree of pension scheme participation. Moreover, the coefficients of the expectation interaction terms with the short-lived dummy are more significant for those individuals who happen to belong to the middle-income group. Perhaps this group better realizes how the two policy options have different effects on short- and long-lived individuals. Individuals in the low-income group also seem to participate more in voluntary pension schemes when they feel that policy changes are likely. This group is especially worried about the level of pension benefits as the AOW-benefits constitute a very large part of their expected pension income. The interactions with the short-lived dummy are less important.

Table 4 provides insights into the fit of the different models for all seven (sub)samples by displaying Akaike's information criteria. The criteria can only be compared within each separate (sub)sample. For the entire sample (column I) model number eight, including both the benefit level $\left(\beta_{i}\right)$ and eligibility age $\left(\delta_{i}\right)$ expectations as well as the interactions with a short-lived dummy, is preferred. This is also the case for the middle age, high age, low income and middle-income sub-samples. For the two sub-categories that didn't display significant reactions in pension scheme participation according to their policy expectations, the low age and high income groups, this is not the case. Model two is preferred when only analyzing young individuals and model seven is preferred when only analyzing the rich, although the 
differences in the Akaike's criteria for these two groups are small.

Overall, the three hypotheses posed in Section 2 can thus not be rejected by the regression results in tables 2 and 3. Participation in voluntary pension schemes is higher for those who assign a high probability to any future change in the PAYG pension scheme. People's expectations regarding a shift in the eligibility age are particularly important. Moreover, conditional on the sum of change expectations, individuals who believe they don't have a long life and who also believe that an increase in the eligibility age is more likely than a decrease in the benefit level, participate more. This can be explained by the fact that the cost of an eligibility age increase will be relatively larger to them. These effects are however not equal for all age and income categories, which can be explained by different time horizons, variation in the relative financial importance of AOW-benefits and differences in the informational value of subjective survival probabilities. The young and those with a relatively high income don't seem to prepare much for a policy change, regardless of how likely they believe such a change will be. The middle-aged and those in the middle-income category seem particularly concerned with an increase in the social security eligibility age, whereas the low-income group responds to a greater extent to their benefit level expectations. The different effects for long- and short-lived individuals are most pronounced in the oldest group and in the middle-income group. 
Table 3: Coefficients of probit models. Dependent: participation in voluntary pension scheme. Low income: lower than EUR 25,150, Middle income: EUR 25,150-EUR 38,100, High income: more than EUR 38,100. Interactions are with the short-lived dummy.

\begin{tabular}{|ll|c|ccc|}
\hline Model & Variable & $(\mathrm{I})$ & $(\mathrm{V})$ & $(\mathrm{VI})$ & $(\mathrm{VII})$ \\
\hline & & All & Low income & Middle income & High income \\
\hline \hline 1a & Beta & 0.241 & $0.712^{* *}$ & 0.333 & -0.445 \\
\hline 2a & Delta & $0.507^{* *}$ & $0.640^{*}$ & $0.767^{* *}$ & 0.136 \\
\hline 3a & Gamma & 0.078 & -0.201 & 0.304 & 0.268 \\
& Sum & $0.269^{* *}$ & $0.458^{* *}$ & $0.401^{*}$ & -0.092 \\
\hline 1b & Beta & $0.481^{*}$ & $1.010^{* *}$ & $0.629^{*}$ & -0.250 \\
& Interaction & $-0.619^{*}$ & -0.750 & -0.724 & -0.548 \\
& Short-lived & 0.090 & 0.209 & 0.218 & -0.095 \\
\hline 2b & Delta & 0.339 & 0.448 & 0.491 & 0.109 \\
& Interaction & 0.454 & 0.510 & 0.710 & 0.081 \\
& Short-lived & $-0.414^{*}$ & -0.399 & -0.475 & -0.371 \\
\hline 3b & Gamma & -0.315 & $-0.860^{*}$ & -0.314 & 0.123 \\
& Interaction & $1.067^{*}$ & -0.630 & $1.474^{*}$ & 0.419 \\
& Sum & $0.265^{* *}$ & 1.286 & $0.380^{*}$ & -0.090 \\
& Short-lived & $-0.778^{* *}$ & $-0.860^{*}$ & $-0.923^{*}$ & -0.558 \\
\hline 4a & Beta & 0.033 & 0.544 & 0.010 & $-0.590^{*}$ \\
& Delta & $0.464^{* *}$ & 0.398 & $0.762^{* *}$ & 0.357 \\
\hline 4b & Beta & 0.411 & $1.022^{* *}$ & 0.518 & -0.347 \\
& Interaction & $-1.013^{* * *}$ & $-1.168^{*}$ & $-1.419^{* *}$ & -0.689 \\
& Delta & 0.168 & -0.029 & 0.279 & 0.237 \\
& Interaction & $0.899^{* *}$ & $1.048^{*}$ & $1.404^{* *}$ & 0.353 \\
& Short-lived & -0.221 & -0.195 & -0.238 & -0.21 \\
\hline $\mathrm{N}$ & & 3228 & 1076 & 1076 & 1076 \\
Ind & & 1114 & 495 & 481 & 421 \\
\hline
\end{tabular}

${ }^{*} p<0.05,{ }^{* *} p<0.01,{ }^{* * *} p<0.001$

Standard errors are clustered at the individual level (table A-4)

All regressions include the short-lived dummy, a constant, log income, education level, age, a child dummy, a partner dummy and year dummies. 
Table 4: Akaike Information Criteria per model and sample

\begin{tabular}{|l|c|c|c|c|c|c|c|}
\hline Model & \multicolumn{7}{|c|}{ Akaike Information Criterion } \\
\hline & $(\mathrm{I})$ & $(\mathrm{II})$ & $(\mathrm{III})$ & $(\mathrm{IV})$ & $(\mathrm{V})$ & $(\mathrm{VI})$ & $(\mathrm{VII})$ \\
\hline & All & Low age & Mid age & Hi Age & Low inc & Mid inc & Hi inc \\
\hline \hline 1 & 4144.8 & 1127.1 & 1400.3 & 1608.2 & 1212.3 & 1434.4 & 1463.7 \\
\hline 2 & 4123.0 & 1127.0 & 1362.7 & 1607.2 & 1216.5 & 1417.7 & 1469.4 \\
\hline 3 & 4131.3 & 1128.5 & 1372.5 & 1603.4 & 1209.7 & 1423.8 & 1469.8 \\
\hline 5 & 4136.9 & 1128.7 & 1394.1 & 1602.0 & 1209.5 & 1431.7 & 1463.4 \\
\hline 6 & 4119.7 & 1128.0 & 1364.4 & 1600.7 & 1216.4 & 1415.5 & 1471.4 \\
\hline 7 & 4119.5 & 1130.2 & 1373.1 & 1589.6 & 1206.3 & 1416.8 & 1471.1 \\
\hline 4 & 4124.9 & 1128.4 & 1364.1 & 1605.9 & 1210.1 & 1419.7 & 1461.9 \\
\hline 8 & 4102.4 & 1131.4 & 1360.4 & 1580.8 & 1202.5 & 1405.6 & 1462.9 \\
\hline \hline $\mathrm{N}$ & 3228 & 931 & 1097 & 1198 & 1076 & 1076 & 1076 \\
\hline
\end{tabular}

\section{Conclusion}

From the 1960s and 1970s onwards economists have been anxious to know whether private savings in industrialized countries had been crowded out by the installment of old age social security systems in the decades before. The future of Pay-As-You-Go pension schemes seemed prosperous at the time and most studies took "continually rising benefit levels (Feldstein, 1974, p. 911)" into account. During the last two decades however, both economists and policy-makers have realized that Western populations are ageing and that this has consequences for the financial sustainability of old age social security systems. Governments in many OECD-countries are now contemplating how to change their public pension schemes so that these can last into the (aged) future. Wherever PAYG- pension schemes are still unaltered there thus exists significant uncertainty about future pension policies. Therefore, it is now relevant to investigate how individuals adapt their private savings to a possible dismantlement of public pension provisions. This does not only shed light on the relationship between public and private savings, but in addition tells us more about how citizens respond to anticipated policy changes.

In this paper I present empirical evidence from The Netherlands, analyzing how subjective probabilities assigned to two different policy changes affect participation in voluntary pension schemes. The empirical evidence (see tables 2 and 3 in Section 4) shows that individuals contribute to a voluntary pension scheme more often when they are more pessimistic about the future of old age social security. This increased participation is most pronounced for individuals who assign a higher probability to a potential increase in the eligibility age, but a small positive effect of the subjective probability assigned to a decrease in benefit levels is also found. These re- 
sults are in accordance with the first two theoretical hypotheses formulated in Section 2. Which of these policy options an individual believes is more likely to occur also matters. Taking the sum of policy change expectations into account, those who believe that an increase in the eligibility age is more likely than a decrease in the benefit level participate slightly more. This effect is however much stronger for those who assign themselves a low survival probability. The third hypothesis from Section 2 is thereby confirmed. My theoretical model explains this through the relative larger cost the shortlived group associates with an eligibility age increase. All of this suggests that individuals indeed prepare for potential policy changes and that policy uncertainty in social security leads to an increase or 'crowding in' of private savings.

Overall, the theoretical predictions from Section 2 are thus confirmed by the regression results in tables 2 and 3 . The effects are however not equal for all age and income categories. The young and those with a relatively high income don't seem to prepare much for a policy change, regardless of how likely they believe such a change will be. Retirement is perhaps too far away for those between 30 and 39 to take current policy expectations into account in their savings decisions. Rich individuals on the other hand probably don't care about the future of public pension benefits as these benefits only amount to a small fraction of their anticipated pension income. The middle-aged and those in the middle-income category do respond strongly to their policy change expectations. They seem particularly concerned with an increase in the social security eligibility age, whereas the low-income group responds to a greater extent to their benefit level expectations. The latter makes sense as social security benefits are by far the largest part of anticipated pension income for this group. The different effects for shortand long-lived individuals are most pronounced in the oldest group and in the middle-income group. Apparently, these groups are better aware of the differential impact of later and lower benefits on different survival groups.

Policy-makers and politicians can learn two things from the above results. First, as people's policy expectations matter for their savings behavior, these expectations should be managed with care to the extent that this is possible. The public debate on the future sustainability of old age social security supposedly influences policy expectations and therefore concern should only be raised if this is somehow justified. Second, the results suggest that wealth effects of policy changes in old age social security will partly be offset by individuals' private pension savings. This finding encourages governments to actually carry out necessary changes to the PAYG pension-system if these are generally expected anyhow.

Although my empirical results are suggestive, the case for a crowding in effect would be stronger if the same results would be replicated using data on the actual level of voluntary contributions. Evidence from other countries about the effect of the (potential) degeneration of the PAYG-pension scheme 
on private savings is also essential to draw definitive conclusions about the crowding in of savings by policy uncertainty in first pillar pensions.

\section{References}

Alessie, R., Kapteyn, A. and Klijn, F.: 1997, Mandatory Pensions and Personal Savings in The Netherlands, De Economist 145(3), 291-324.

Attanasio, O. and Brugiavini, A.: 2003, Social Security and Savings, The Quarterly Journal of Economics 118(3), p. 1075-1119.

Attanasio, O. and Rohwedder, S.: 2003, Pension Wealth and Household Saving: Evidence from Pension Reforms in the United Kingdom, American Economic Review 93(5), p. 1499-1521.

Boersch-Supan, A.: 2005, Mind the Gap: The Effectiveness of Incentives to Boost Retirement Saving in Europe, OECD Economic Studies 39(2).

Bowman, D., Minehart, D. and Rabin, M.: 1999, Loss Aversion in a Consumption-Savings Model, Journal of Economic Behavior and Organization 38, 155-178.

Browning, M. and Lusardi, A.: 1996, Household saving: Micro theories and micro facts, Journal of Economic Literature 34(4), 1797-1855.

Dominitz, J., Manski, C. and Heinz, J.: 2002, Social Security Expectations and Retirement Savings Decisions, JCPR Working Papers 273, Northwestern University/University of Chicago Joint Center for Poverty Research.

Dominitz, J., Manski, C. and Heinz, J.: 2003, "Will Social Security be there for you?": How Americans Perceive their Benefits, NBER Working Papers 9798, National Bureau of Economic Research.

Euwals, R.: 2000, Do Mandatory Pensions Decrease Household Savings; Evidence for The Netherlands, De Economist 148(5), 643-670.

Feldstein, M.: 1974, Social Security, Induced Retirement, and Aggregate Capital Accumulation, The Journal of Political Economy 82(5), 905926.

Guariglia, A. and Markose, S.: 2000, Voluntary Contributions to Personal Pension Plans: Evidence from the British Household Panel survey, Fiscal Studies 21(4), 469-488.

Guiso, L., Jappelli, T. and Terlizzese, D.: 1992, Earnings Uncertainty and Precautionary Saving, Journal of Monetary Economics 30(2), 307-337. 
Hurd, M. and McGarry, K.: 2002, The Predictive Validity of Subjective Probabilities of Survival, The Economic Journal 112(482), 966-985.

Jappelli, T.: 1995, Does Social Security Reduce the Accumulation of Private Wealth? Evidence from Italian Survey Data, Ricerche Economiche 49(1), 1-31.

Kapteyn, A., Alessie, R. and Lusardi, A.: 2003, Explaining the Wealth Holdings of Different Cohorts: Productivity Growth and Social Security, European Economic Review 49(5), 1361-1391.

Kotlikoff, L.: 1979, Testing the Theory of Social Security and Life Cycle Accumulation, American Economic Review 69(3), 396-410.

Manski, C. F.: 2004, Measuring Expectations, Econometrica 72(5), 13291376 .

Stephens, M.: 2004, Job Loss Expectations, Realizations, and Household Consumption Behavior, The Review of Economics and Statistics 86(1), 253-269.

van Eekelen, L.: 2006, Handboek AOW, SVB, Amstelveen, chapter De Betaalbaarheid van de AOW.

\section{A Algebraic results}

This appendix displays optimal savings equations resulting from the model described in Section 2.

The following savings level is optimal when the government chooses between the status quo (A) with probability $\left(1-\beta_{i}\right)$ and lower benefits (B) with probability $\beta_{i}$ (A or B model).

$$
\begin{array}{r}
S_{i}^{*, A o r B}=\frac{1}{6}\left(-8 P+2 I_{i}+6 P \lambda-4 P \beta_{i} \lambda+\right. \\
\sqrt{ }\left(\left(-8 P+2 I_{i}+6 P \lambda-4 P \beta_{i} \lambda\right)^{2}+\right. \\
\left.\left.12\left(-4 P^{2}+4 P I_{i}+4 P^{2} \lambda-4 P I_{i} \lambda+4 P I_{i} \beta_{i} \lambda\right)\right)\right)
\end{array}
$$

Normalizing the benefit level $\mathrm{P}$ to be equal to one and income to be equal to two this becomes:

$$
S_{i}^{*, A o r B}=\frac{1}{6}\left(-4+6 \lambda-4 \beta_{i} \lambda+\sqrt{\left(-4+6 \lambda-4 \beta_{i} \lambda\right)^{2}+12\left(4-4 \lambda+8 \beta_{i} \lambda\right)}\right)
$$

The savings below are optimal when the government chooses between the status quo with probability $\left(1-\delta_{i}\right)$ and an increase in the eligibility age with probability $\delta_{i}$ (A or $\mathrm{C}$ model).

$$
\begin{array}{r}
S_{i}^{*, \text { Aor } C}=\frac{1}{6}\left(-5 P-2 \delta_{i} P+2 I+\right. \\
\left.\sqrt{P^{2}+20 \delta_{i} P^{2}+4 \delta_{i}^{2} P^{2}+4 P I_{i}+16 \delta_{i} P I_{i}+4 I_{i}^{2}}\right)
\end{array}
$$


Normalizing the benefit level $\mathrm{P}$ to be equal to one and income to be equal to two this becomes:

$$
S_{i}^{*, A o r C}=\frac{1}{6}\left(-1-2 \delta_{i}+\sqrt{25+52 \delta_{i}+4 \delta_{i}^{2}}\right)
$$

The following equation displays optimal savings when there will certainly be a policy change but it is uncertain which option the government will choose, either lower benefits with probability $\left(1-\gamma_{i}\right)$ or an increase in the eligibility age with probability $\gamma_{i}=\frac{\delta_{i}}{\delta_{i}+\alpha_{i}}$ (the $\mathrm{B}$ or $\mathrm{C}$ model).

$$
\begin{array}{r}
S_{i}^{*, B o r C}=\frac{1}{6}\left(-5 P+2 I_{i}-2 P \gamma_{i}+2 P \lambda+4 P \gamma_{i} \lambda+\right. \\
\sqrt{ }\left(\left(-5 P+2 I_{i}-2 P \gamma_{i}+2 P \lambda+4 P \gamma_{i} \lambda\right)^{2}+\right. \\
\left.\left.12\left(-2 P^{2}+2 P I_{i}+2 P I_{i} \gamma_{i}+2 P^{2} \lambda-4 P I_{i} \gamma_{i} \lambda\right)\right)\right)
\end{array}
$$

Normalizing the benefit level $\mathrm{P}$ to be equal to one and income to be equal to two this becomes:

$$
\begin{array}{r}
S_{i}^{*, \text { Bor } C}=\frac{1}{6}\left(-1-2 \gamma_{i}+2 \lambda+4 \gamma_{i} \lambda+\right. \\
\left.\sqrt{12\left(2+4 \gamma_{i}+2 \lambda-8 \gamma_{i} \lambda\right)+\left(-1-2 \gamma_{i}+2 \lambda+4 \gamma_{i} \lambda\right)^{2}}\right)
\end{array}
$$

The equation for optimal savings of short-lived individuals (those that know they will die after the second period) when there is uncertainty between policy option B (lower benefits) and policy option C (later benefits) is depicted in the following equation.

$$
\begin{array}{r}
S_{i}^{*, \text { Bor } C, \text { short }}=\frac{1}{4}\left(-P+I_{i}-P \gamma_{i}+P \lambda+P \gamma_{i} \lambda+\right. \\
\left.\sqrt{\left(-P+I-P \gamma_{i}+P \lambda+P \gamma_{i} \lambda\right)^{2}+8\left(P I_{i} \gamma-P I_{i} \gamma_{i} \lambda\right)}\right)
\end{array}
$$

Normalizing the benefit level $\mathrm{P}$ to be equal to one and income to be equal to two this becomes:

$$
S_{i}^{*, \text { Bor } C, \text { short }}=\frac{1}{4}\left(1-\gamma_{i}+\lambda+\gamma_{i} \lambda+\sqrt{8\left(2 \gamma_{i}-2 \gamma_{i} \lambda\right)+\left(1-\gamma_{i}+\lambda+\gamma_{i} \lambda\right)^{2}}\right)
$$

\section{B Figures}


Figure A-1: Integer survival probabilities up to age $75(\mathrm{~N}=3,228)$

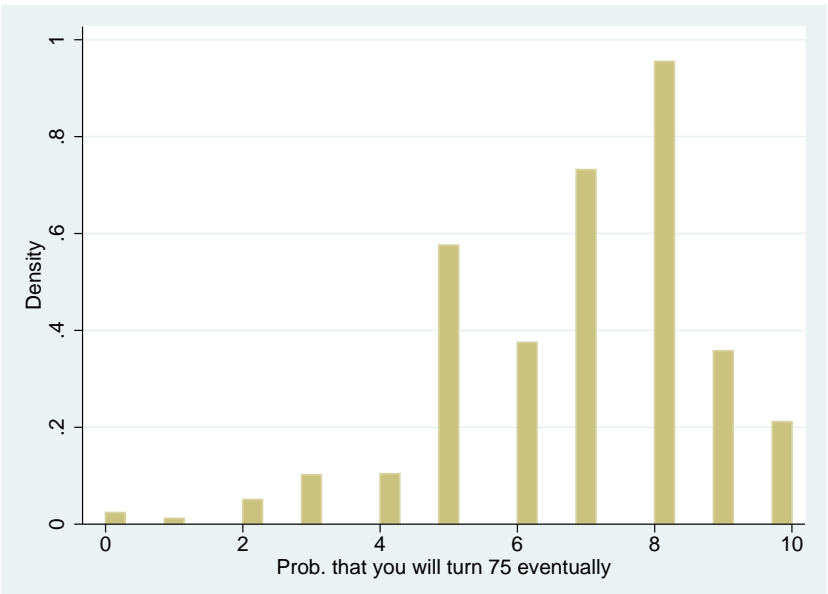

Figure A-2: Lowess smoothing graph of average survival probabilities up to age 75 for different ages and sex $(\mathrm{N}=3,228)$

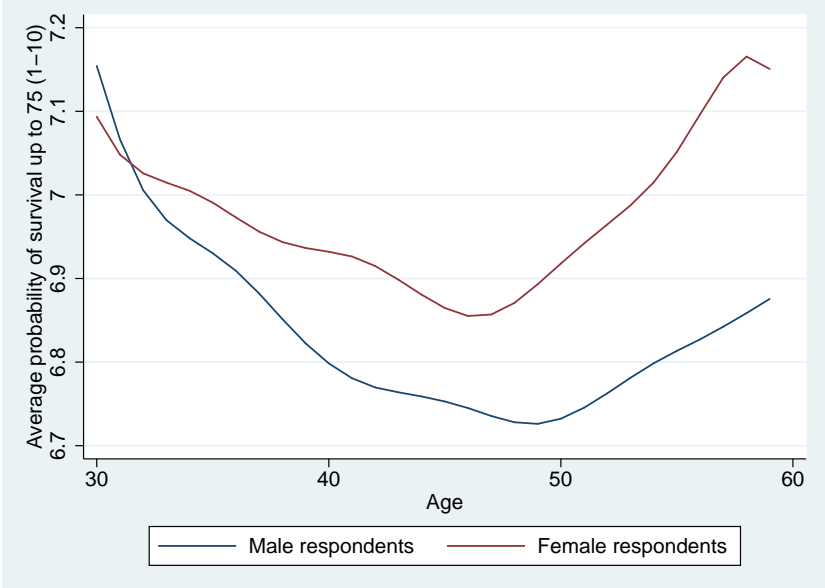




\section{Summary statistics}

Table A-1: Descriptive statistics of dependent and independent variables in the estimations for different age groups.

\begin{tabular}{|l|c|c|c|c|c|c|}
\hline & \multicolumn{2}{|c|}{ (II) } & \multicolumn{2}{c|}{ (III) } & \multicolumn{2}{c|}{ (IV) } \\
\hline & \multicolumn{2}{|c|}{ Low age } & Middle age & \multicolumn{2}{c|}{ High age } \\
\hline & Mean & Sd & Mean & Sd & Mean & Sd \\
\hline \hline Dummy pension participation & 0.321 & 0.467 & 0.365 & 0.482 & 0.463 & 0.499 \\
\hline Prob. of lower benefits $\left(\beta_{i}\right)$ & 0.442 & 0.230 & 0.426 & 0.238 & 0.395 & 0.247 \\
\hline Prob. of later benefits $\left(\delta_{i}\right)$ & 0.539 & 0.227 & 0.531 & 0.230 & 0.529 & 0.261 \\
\hline Ratio later over lower $\left(\gamma_{i}\right)$ & 0.557 & 0.144 & 0.567 & 0.163 & 0.580 & 0.185 \\
\hline Sum of change expectations & 0.981 & 0.395 & 0.957 & 0.392 & 0.924 & 0.428 \\
\hline Dummy for short-lived & 0.408 & 0.492 & 0.388 & 0.488 & 0.384 & 0.487 \\
\hline Log of gross income & 9.904 & 1.843 & 9.742 & 2.346 & 9.934 & 2.149 \\
\hline Age & 34.290 & 2.821 & 44.813 & 2.814 & 54.325 & 2.827 \\
\hline Dummy for female & 0.437 & 0.496 & 0.428 & 0.495 & 0.356 & 0.479 \\
\hline Dataset 2003 & 0.148 & 0.356 & 0.160 & 0.367 & 0.155 & 0.362 \\
\hline Dataset 2004 & 0.189 & 0.392 & 0.203 & 0.403 & 0.182 & 0.386 \\
\hline Dataset 2005 & 0.218 & 0.413 & 0.215 & 0.411 & 0.215 & 0.411 \\
\hline Dataset 2006 & 0.205 & 0.404 & 0.213 & 0.410 & 0.225 & 0.418 \\
\hline Dataset 2007 & \multicolumn{7}{|c|}{ Omitted category } \\
\hline Primary education & \multicolumn{7}{|c|}{ Omitted category } \\
\hline Secondary education & 0.226 & 0.418 & 0.342 & 0.475 & 0.421 & 0.494 \\
\hline Vocational education & 0.293 & 0.455 & 0.248 & 0.432 & 0.163 & 0.370 \\
\hline Tertiary education & 0.456 & 0.498 & 0.377 & 0.485 & 0.383 & 0.486 \\
\hline Other education & 0.021 & 0.145 & 0.010 & 0.100 & 0.002 & 0.041 \\
\hline Dummy for child & 0.534 & 0.499 & 0.603 & 0.490 & 0.358 & 0.480 \\
\hline Dummy for partner & 0.716 & 0.451 & 0.754 & 0.431 & 0.762 & 0.426 \\
\hline \hline Observations & 931 & \multicolumn{7}{|c|}{1097} & & 1198 & \\
\hline & & \multicolumn{7}{c}{} & \\
\hline
\end{tabular}


Table A-2: Descriptive statistics of dependent and independent variables in the estimations for different income groups.

\begin{tabular}{|l|c|c|c|c|c|c|}
\hline Variable & \multicolumn{2}{|c|}{$(\mathrm{V})$} & \multicolumn{2}{c|}{$(\mathrm{VI})$} & \multicolumn{2}{c|}{$(\mathrm{VII})$} \\
\hline & \multicolumn{2}{|c|}{ Low income } & \multicolumn{1}{c|}{ Middle income } & \multicolumn{2}{c|}{ High income } \\
\hline & Mean & Sd & Mean & Sd & Mean & Sd \\
\hline \hline Dummy pension participation & 0.267 & 0.442 & 0.407 & 0.492 & 0.493 & 0.500 \\
\hline Prob. of lower benefits $\left(\beta_{i}\right)$ & 0.421 & 0.253 & 0.430 & 0.241 & 0.405 & 0.224 \\
\hline Prob. of later benefits $\left(\delta_{i}\right)$ & 0.538 & 0.249 & 0.549 & 0.239 & 0.511 & 0.233 \\
\hline Ratio later over lower $\left(\gamma_{i}\right)$ & 0.573 & 0.168 & 0.569 & 0.168 & 0.564 & 0.165 \\
\hline Sum of change expectations & 0.959 & 0.429 & 0.979 & 0.407 & 0.917 & 0.381 \\
\hline Dummy for short-lived & 0.415 & 0.493 & 0.389 & 0.488 & 0.373 & 0.484 \\
\hline Log of gross income & 8.377 & 3.198 & 10.367 & 0.108 & 10.836 & 0.265 \\
\hline Age & 44.849 & 8.650 & 44.612 & 8.701 & 46.482 & 8.211 \\
\hline Dummy for female & 0.724 & 0.447 & 0.335 & 0.472 & 0.152 & 0.360 \\
\hline Dataset 2003 & 0.164 & 0.370 & 0.147 & 0.354 & 0.154 & 0.361 \\
\hline Dataset 2004 & 0.192 & 0.394 & 0.185 & 0.388 & 0.196 & 0.397 \\
\hline Dataset 2005 & 0.213 & 0.409 & 0.225 & 0.418 & 0.210 & 0.408 \\
\hline Dataset 2006 & 0.207 & 0.406 & 0.237 & 0.425 & 0.202 & 0.401 \\
\hline Dataset 2007 & \multicolumn{7}{|c|}{ Omitted category } \\
\hline Primary education & \multicolumn{7}{|c|}{ Omitted category } \\
\hline Secondary education & 0.442 & 0.497 & 0.356 & 0.479 & 0.215 & 0.411 \\
\hline Vocational education & 0.295 & 0.456 & 0.246 & 0.431 & 0.148 & 0.355 \\
\hline Tertiary education & 0.209 & 0.407 & 0.370 & 0.483 & 0.627 & 0.484 \\
\hline Other education & 0.010 & 0.101 & 0.019 & 0.135 & 0.002 & 0.043 \\
\hline Dummy for child & 0.562 & 0.496 & 0.436 & 0.496 & 0.478 & 0.500 \\
\hline Dummy for partner & 0.798 & 0.401 & 0.675 & 0.469 & 0.765 & 0.424 \\
\hline \hline Observations & 1076 & \multicolumn{7}{|c|}{1076} & & 1076 & \\
\hline
\end{tabular}


Table A-3: Standard errors of probit models. Dependent: participation in voluntary pension scheme.

\begin{tabular}{|ll|c|ccc|}
\hline Model & Variable & $(\mathrm{I})$ & $(\mathrm{II})$ & $(\mathrm{III})$ & $(\mathrm{IV})$ \\
\hline & & All & Low age & Middle age & High age \\
\hline \hline 1a & Beta & 0.159 & 0.268 & 0.269 & 0.260 \\
\hline 2a & Delta & 0.163 & 0.281 & 0.286 & 0.246 \\
\hline 3a & Gamma & 0.238 & 0.448 & 0.410 & 0.345 \\
& Sum & 0.097 & 0.164 & 0.170 & 0.150 \\
\hline 1b & Beta & 0.191 & 0.349 & 0.327 & 0.314 \\
& Interaction & 0.268 & 0.462 & 0.450 & 0.448 \\
& Short-lived & 0.132 & 0.223 & 0.228 & 0.205 \\
\hline 2b & Delta & 0.191 & 0.351 & 0.343 & 0.285 \\
& Interaction & 0.289 & 0.470 & 0.528 & 0.446 \\
& Short-lived & 0.172 & 0.277 & 0.312 & 0.26 \\
\hline 3b & Gamma & 0.267 & 0.543 & 0.470 & 0.390 \\
& Interaction & 0.422 & 0.740 & 0.749 & 0.650 \\
& Sum & 0.098 & 0.164 & 0.170 & 0.153 \\
& Short-lived & 0.252 & 0.435 & 0.449 & 0.393 \\
\hline 4a & Beta & 0.176 & 0.301 & 0.295 & 0.286 \\
& Delta & 0.179 & 0.316 & 0.312 & 0.270 \\
\hline 4b & Beta & 0.210 & 0.390 & 0.360 & 0.336 \\
& Interaction & 0.305 & 0.530 & 0.524 & 0.497 \\
& Delta & 0.209 & 0.395 & 0.373 & 0.304 \\
& Interaction & 0.323 & 0.539 & 0.598 & 0.483 \\
& Short-lived & 0.177 & 0.291 & 0.32 & 0.268 \\
\hline \hline $\mathrm{N}$ & & 3228 & 931 & 1097 & 1198 \\
\hline
\end{tabular}


Table A-4: Standard errors of probit models. Dependent: participation in voluntary pension scheme.

\begin{tabular}{|ll|c|ccc|}
\hline Model & Variable & $(\mathrm{I})$ & $(\mathrm{V})$ & $(\mathrm{VI})$ & $(\mathrm{VII})$ \\
\hline & & All & Low income & Middle income & High income \\
\hline \hline 1a & Beta & 0.159 & 0.249 & 0.259 & 0.272 \\
\hline 2a & Delta & 0.163 & 0.251 & 0.256 & 0.276 \\
\hline 3a & Gamma & 0.238 & 0.410 & 0.396 & 0.383 \\
& Sum & 0.097 & 0.144 & 0.158 & 0.169 \\
\hline 1b & Beta & 0.191 & 0.309 & 0.308 & 0.326 \\
& Interaction & 0.268 & 0.418 & 0.436 & 0.484 \\
& Short-lived & 0.132 & 0.216 & 0.224 & 0.22 \\
\hline 2b & Delta & 0.191 & 0.299 & 0.300 & 0.314 \\
& Interaction & 0.289 & 0.419 & 0.461 & 0.522 \\
& Short-lived & 0.172 & 0.257 & 0.283 & 0.296 \\
\hline 3b & Gamma & 0.267 & 0.449 & 0.441 & 0.436 \\
& Interaction & 0.422 & 0.707 & 0.733 & 0.711 \\
& Sum & 0.098 & 0.144 & 0.161 & 0.170 \\
& Short-lived & 0.252 & 0.42 & 0.429 & 0.43 \\
\hline 4a & Beta & 0.176 & 0.290 & 0.290 & 0.287 \\
& Delta & 0.179 & 0.293 & 0.282 & 0.294 \\
\hline 4b & Beta & 0.210 & 0.359 & 0.339 & 0.344 \\
& Interaction & 0.305 & 0.506 & 0.521 & 0.519 \\
& Delta & 0.209 & 0.344 & 0.328 & 0.333 \\
& Interaction & 0.323 & 0.513 & 0.530 & 0.558 \\
& Short-lived & 0.177 & 0.254 & 0.294 & 0.311 \\
\hline \hline $\mathrm{N}$ & & 3228 & 1076 & 1076 & 1076 \\
\hline
\end{tabular}

